\title{
Contribution of the external anal sphincter to the pressure zone in the anal canal
}

\author{
H. L. DUTHIE' AND J. M. WATTS \\ From the University Department of Surgery, General Infirmary, Leeds
}

EDITORIAL SYNOPSIS A study of pressure in the anal canal and of electromyographic activity of the external anal sphincter before and after muscular paralysis has shown that the external anal sphincter contributes to the pressure only when a bolus is within the anal canal.

It is well known both by clinical examination and by objective measurement that a high pressure zone is to be found in the anal canal, due to the action of the anal sphincteric muscles. Division of part of the internal anal sphincter in the operation of internal sphincterotomy resulted in a diminution in this pressure zone (Bennett and Duthie, 1964). The pressure remaining after internal sphincterotomy was thought to be due to the action of the external anal sphincter since this muscle has been shown by electromyography to be in a constant state of tonic activity (Floyd and Walls, 1953; Taverner and Smiddy, 1959). In the present study, the contribution of the external anal sphincter to the pressure zone in the anal canal has been investigated.

\section{MATERIAL AND METHODS}

Twenty male patients, aged 20 to 50 years, without anorectal pathology were studied, first when conscious, again a day or so later under light anaesthesia before an abdominal operation, and finally after the administration of a muscle relaxant which was either succinylcholine or gallamine triethiodide. With the patient lying in the left lateral position, fine polythene tubes $(2 \mathrm{~mm}$. in external diameter) were placed in the rectum through a sigmoidoscope. Usually, two tubes were used: one with a balloon, $5 \times 7 \mathrm{~cm}$., placed at least $10 \mathrm{~cm}$. from the anal verge, the rectal balloon; the second water-filled with either an open end or tipped with a water-filled balloon $5 \times 10 \mathrm{~mm}$. $A$ new balloon was used for each test and all air bubbles were washed out of the system before tying the balloon on the tube. The second tube was withdrawn through the ano-rectum in steps of $0.5 \mathrm{~cm}$., pressure being recorded from both tubes via Stathan strain gauges (Pe $23 \mathrm{gb}$ ). A concentric needle electrode was inserted into the external anal sphincter and the electrical activity passed through a pre-amplifier (Tektronix 122) to a loudspeaker and was also recorded on photographic paper. The muscle relaxant was taken to be fully effective when all electrical

'Present address: University Department of Surgery, The Royal Infirmary, Sheffield, 6 activity ceased in the external anal sphincter. Two main studies were performed: the first was with the patient at rest; in the second the response of the pressure in the anal canal was noted when the rectal balloon at $10 \mathrm{~cm}$. from the anal verge was inflated with $100 \mathrm{ml}$. of air, the maximal change in pressure being recorded together with the electrical activity of the external anal sphincter.

\section{RESULTS}

PRESSURE RECORDINGS AT REST In the 10 subjects studied with the open-ended tubes, administration of light general anaesthesia and the later addition of full muscular relaxation resulted in a diminution of 6 to $12 \mathrm{~mm} . \mathrm{Hg}$ in the mean pressure within the anal canal compared with that in the conscious subject (Fig. 1). These changes were significant at the $5 \%$ level at 2 and $3 \mathrm{~cm}$. from the anal verge. No significant difference was observed between the measurements made with the subjects under general

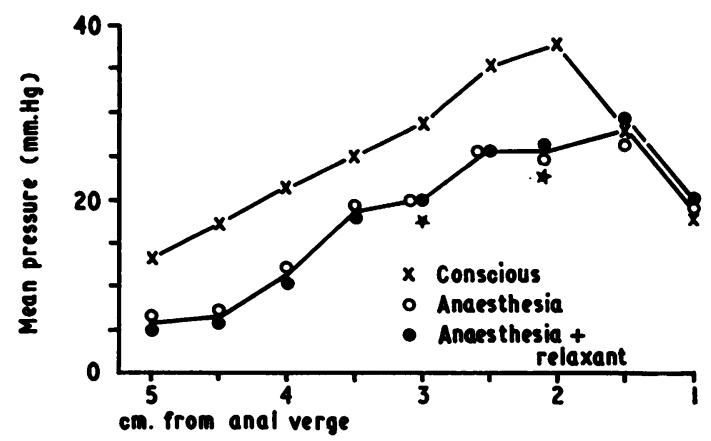

FIG. 1. Mean pressure in the lower rectum and anal canal recorded via an open-ended tube in 10 subjects when conscious, when anaesthetized, and when anaesthetized and fully paralysed. The diminution in pressure from the conscious level is probably significant $(P<0.05)$ at 2 and $3 \mathrm{~cm}$. from the anal verge. 


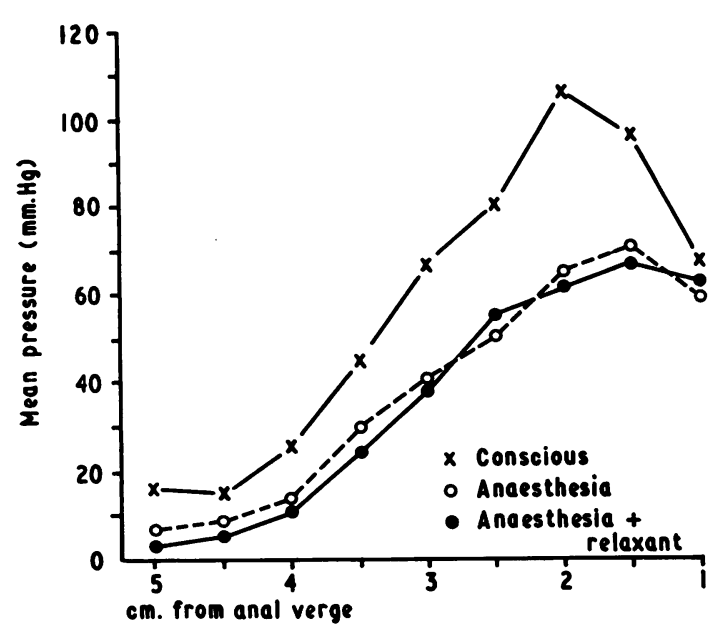

FIG. 2. Mean pressure in the lower rectum and anal canal recorded via a small balloon $(5 \times 10 \mathrm{~mm}$. $)$ in 10 subjects when conscious, when anaesthetized, and when anaesthetized and fully paralysed. The diminution in pressure from the conscious level is significant $(P<0.01$ at 1.5 to $4 \mathrm{~cm}$. from the anal verge inclusive $P<0.02$ at $4.5 \mathrm{~cm}$. from the anal verge).

anaesthesia alone and after paralysis of the external anal sphincter.

In the studies made using the small balloon as the recording unit, a significant decrease from normal mean pressure was found in the anal canal both after giving a general anaesthetic and when a muscle relaxant was given (Fig. 2). These differences were significant at the 0.1 or $1 \%$ level, except at $4.5 \mathrm{~cm}$. from the anal verge which was significant at the $2 \%$ level and at 1 and $5 \mathrm{~cm}$. from the anal verge which were not significant. Even though the mean pressure in the anal canal was significantly diminished, a study of the individual tracings showed a diminution of only $5 \mathrm{~mm}$. of mercury in two of the 10 subjects. It was also observed that the diameter of the balloon appeared to be critical in demonstrating this decrease in pressure. If a balloon $3 \mathrm{~mm}$. in diameter was used the initial pressure in the anal canal with the patient conscious was proportionately smaller and no clear decrease in pressure was observed under anaesthesia or with muscular paralysis. As with the open-ended tube, no significant difference was found between the mean pressures in the anal canal with general anaesthesia alone and with the addition of muscular paralysis.

ELECTROMYOGRAPHY AT REST Although electrical activity was still present in the external anal sphincter after induction of general anaesthesia, the potential of the muscle spikes was reduced from 0.6-2 millivolts to $0 \cdot 1-0 \cdot 5$ millivolts, the frequency remaining at $2-5 / \mathrm{sec}$; furthermore, it was much more difficult to obtain a clear record showing precise motor units, search having to be made for several minutes with the needle electrode.

PRESSURE RECORDING AFTER DISTENSION OF THE RECTUM Inflation of the rectal balloon with $100 \mathrm{ml}$. of air produced initial pressures of 50 to $60 \mathrm{~mm}$. of mercury which tended to fall by 5 to $10 \mathrm{~mm}$. in the 10 to 20 seconds of inflation as the rectum adapted itself to the balloon. In response to this inflation the pressure throughout the anal canal diminished from the resting level whether the external anal sphincter was fully active or not. This diminution was observed in the 10 subjects tested with the openended tube (Fig. 3) and in the 10 tested with the small balloon (Fig. 4). In both groups the level of pressure to which the relaxation took place was similar whether the patient was conscious, anaesthetized, or anaesthetized and fully paralysed (Fig. 5).

ELECTROMYOGRAPHY AFTER DISTENSION OF THE RECTUM Both in the conscious and in the anaesthetized patient, an increase in the electrical activity of the external anal sphincter was observed for three to 20 seconds after inflation of the rectal balloon and again for three to 20 seconds after deflation of the balloon. The frequency during this increased

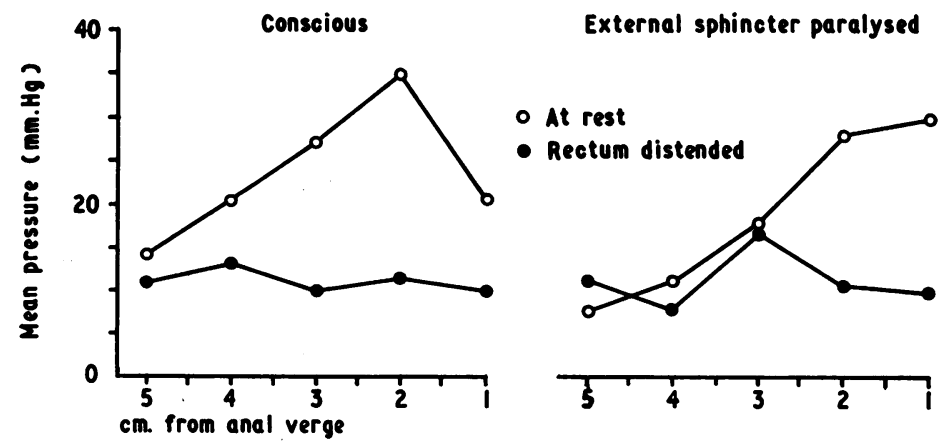

FIG. 3. Mean pressure in the anal canal recorded via an open-ended tube showing relaxation in response to distension of the rectum in 10 subjects. The relaxation reaches similar levels both when the subjects are conscious and when the external anal sphincter is fully paralysed. 


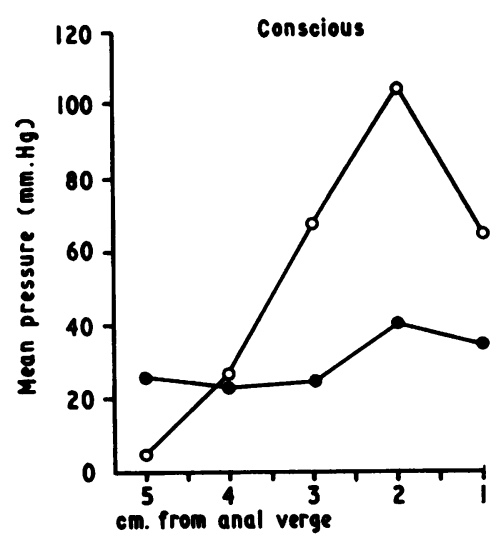

- At rest

- Rectum distended

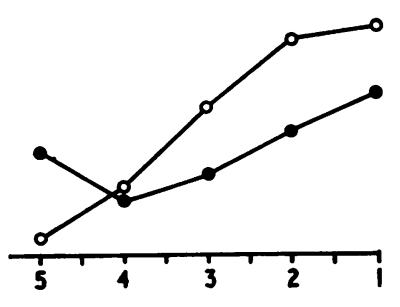

FIG. 4. Mean pressure in the anal canal recorded via a small balloon $(5 \times 10 \mathrm{~mm}$.) showing relaxation in response to distension of the rectum in 10 subjects. The relaxation reaches similar levels both when the subjects are conscious and when the external anal sphincter is fully paralysed.
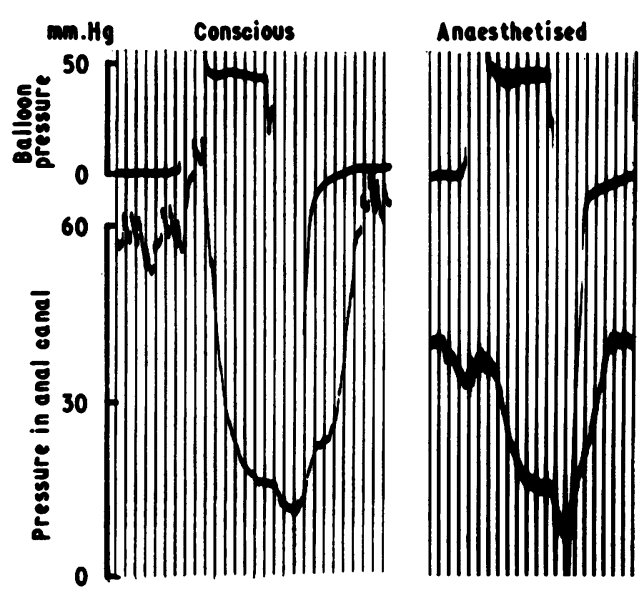

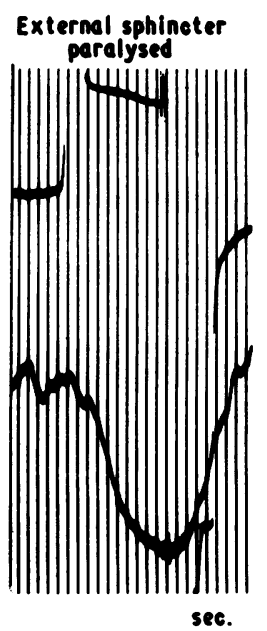

FIG. 5. Tracings of pressure in the anal canal at $3 \mathrm{~cm}$. from the anal verge recorded via a small balloon $(5 \times 10 \mathrm{~mm}$.) showing that whether the subject is conscious, anaesthetized, or anaesthetized and fully paralysed, relaxation occurs to the same pressure levels in response to inflation of the rectal balloon placed $10 \mathrm{~cm}$. from the anal verge (balloon pressure tracing). activity rose up to as much as $12 / \mathrm{sec}$. during anaesthesia, but reached over $15 / \mathrm{sec}$. in the conscious subject. No inhibition of the electromyogram was seen at these pressures, although transient inhibition was seen in two cases when pressures in the region of 80 to $100 \mathrm{~mm}$. of mercury were produced by inflating the rectal balloon with 200 to $300 \mathrm{ml}$. of air. With these volumes of air the conscious patients were complaining bitterly of hypogastric pain.

\section{DISCUSSION}

The failure to demonstrate a significant diminution in pressure within the anal canal as recorded by means of open-ended tubes when the external anal sphincter was paralysed was at variance with clinical experience in digital examination of the rectum when much less resistance is felt with the patients under anaesthesia. This was the reason for testing the further 10 patients with the small balloon to provide a larger bolus in the anal canal. In this circumstance the external anal sphincter was shown to play an appreciable part in producing the pressure within the anal canal because paralysis of the muscle was accompanied by an obvious and significant fall in pressure. In both groups the decrease in pressure extended up into the lower part of the rectum 5 to $6 \mathrm{~cm}$. from the anal verge although it was not statistically significant at this level. This was taken to indicate a general muscular relaxation affecting intra-abdominal pressure rather than any specific local effect on the ano-rectal musculature.

At first sight, the similarity of the pressure in the anal canal under anaesthesia with and without muscular paralysis was paradoxical; one would expect a further decrease in pressure when the external sphincter was paralysed. However, the reduced amplitude and difficulty in recording the electrical activity in the external anal sphincter under anaesthesia were suggestive that a much 
smaller number of motor units were active compared with the conscious state and it would seem that they were not functionally effective.

The reflex decrease of pressure observed in the anal canal in response to rectal distension is well documented (Denny-Brown and Robertson, 1935) and has been thought to enable the somatic sensory area in the anal canal to play a part in discrimination of the nature of rectal contents (Duthie and Bennett, 1963). Previous work has been concentrated on the role of the internal anal sphincter in this reflex (Denny-Brown and Robertson, 1935; Schuster, Hendrix, and Mendeloff, 1963). and it has been shown still to occur when the external anal sphincter is paralysed, for example, in a patient with a lesion of the cauda equina. We have been able to compare this reflex in the same patient before and after paralysis of the external anal sphincter. When recording with the open-ended tube, the pressure at rest in the anal canal was not greatly altered by paralysis of the external anal sphincter, and, in keeping with this, the level of pressure to which relaxation occurred was similar before and after the muscle was inactivated. Relaxation was not complete, however, and it is not yet clear to what may be attributed the remaining pressure.

Although the initial pressure in the anal canal was diminished by paralysis of the external anal sphincter when the small balloon was used as the recording unit, the pressure to which the anal canal relaxed was similar whether the external sphincter was active or not. Thus, it would seem that the external anal sphincter takes no part in this relaxation response. The observations are somewhat confusing, because if the fall in pressure due to rectal distension was entirely the result of relaxation of the internal sphincter, the extent of fall might be expected to be the same whether the external sphincter was paralysed or not. A major part of the fall in pressure occurs when the muscle has been paralysed so that the internal sphincter must be largely if not wholly responsible for the relaxation. Our findings do not confirm the results of Gaston (1948) who used a large obturator $(2.5 \mathrm{~cm}$. in diameter) in the anal canal and found, on distending the rectum, that the pressure increased in the distal part of the anal canal; he attributed this increase to the action of the external anal sphincter. It is likely that this discrepancy is because of the different recording units used.

Further evidence of the inability of the external anal sphincter to influence the relaxation reflex in the anal canal came from the electromyographic studies. In response to rectal distension, the external anal sphincter showed an increased activity at the very time that the maximal rate of diminution in pressure occurred. We could only produce inhibition of the electrical activity in the external anal sphincter after about a minute of further distension of the rectum, by which time the pressure was increasing again in the anal canal. This inhibition of electrical activity in the external anal sphincter is also found in the muscles of the pelvic floor and has been fully described and investigated by Porter (1961) who felt that it is an important reflex in the maintenance of continence. The peak of pressure remaining at 1.0 to $2.0 \mathrm{~cm}$. from the anal verge after rectal distension was initially thought to be due to the external anal sphincter but this has not been substantiated. It may be that a differential relaxation occurs in the internal anal sphincter, the more distal fibres retaining more activity.

There appeared to be at least three components in the pressure recorded from the anal canal. 1 The external sphincter plays little or no part in the pressure recorded by an open tube, but plays some part in that recorded by a small balloon. 2 The rectal distension produced a fall in anal canal pressure which may involve the external sphincter to a slight extent but which is largely due to the internal sphincter. 3 A third component remains, after rectal distension and paralysis of the external sphincter, which is slightly higher when recorded by a balloon than by an open tube. The smaller the balloon the smaller this difference appears to be. It might be that this component is connected with the physical characteristics of the anal canal rather than with any muscular activity.

The role of the external anal sphincter in producing the pressure within the anal canal depended on the size of the recording unit, and was only appreciable when the larger recording unit $(5 \mathrm{~mm}$. in diameter) was used. To attempt to translate these findings in a functional manner, it is suggested that at rest the continued tonic activity of the external anal sphincter is a reflexion of the postural action of the muscles of the pelvic floor and does not contribute to anal continence. The external anal sphincter comes into play in maintaining continence only when a bolus enters the upper part of the anal canal. In addition, voluntary anal continence is maintained by the external anal sphincter, but it is well known that this voluntary control can only be maintained for about a minute.

\section{SUMMARY}

Pressure in the anal canal has been recorded via open-ended or balloon-tipped $(5 \times 10 \mathrm{~mm}$.) tubes connected to strain gauges in 20 subjects when conscious, when anaesthetized, and when anaesthetized and fully paralysed, in order to assess the function of the external anal sphincter. The electrical 
activity of the external anal sphincter was also recorded.

When open-ended tubes were used to record the pressure, paralysis of the external anal sphincter made only a slight diminution to the pressure within the anal canal. A significant decrease in this pressure was observed with the small balloon as the recording unit. Relaxation in the anal canal in response to distension of the upper rectum was independent of the action of the external anal sphincter. It is suggested that the external anal sphincter only contributes to the pressure within the anal canal when a bolus is present.

We thank Dr. D. Taverner for his assistance with the electromyographic apparatus and Professor J. C. Goligher for his advice and criticism.

\section{REFERENCES}

Bennett, R. C., and Duthie, H. L. (1964). The functional importance of the internal anal sphincter. Brit. J. Surg., 51, 355-357.

Denny-Brown, D., and Robertson, E. G. (1935). An investigation of the nervous control of defaecation. Brain, 58, 256-310.

Duthie, H. L., and Bennett, R. C. (1963). The relation of sensation in the anal canal to the functional anal sphincter: a possible factor in anal continence. Gut, 4, 179-182.

Floyd, W. F., and Walls, E. W. (1953). Electromyography of the sphincter ani externus in man. J. Physiol., 122, 599-609.

Gaston, E. A. (1948). The physiology of fecal continence. Surg. Gynec. Obstet., 87, 280-290.

Porter, N. H. (1961). Megacolon: a physiological study. Proc. roy. Soc. Med., 54, 1043-1047.

Schuster, M. M., Hendrix, T. R., and Mendeloff, A. I. (1963). The internal anal sphincter response: manometric studies on its normal physiology, neural pathways, and alteration in bowel disorders. J. clin. Invest., 42, 196-207.

Taverner, D., and Smiddy, F. G. (1959). An electromyographic study of the normal function of the external anal sphincter and pelvic diaphragm. Dis. Colon Rect., 2, 153-160. 